\title{
CAPILARIDADE E INSERÇÃO DAS PRÁTICAS AUXILIARES E TÉCNICAS DE ENFERMAGEM NA ATENÇÃO BÁSICA
}

\author{
Luciana de Oliveira \\ Graduanda em enfermagem pela Faculdade de Enfermagem da Unicamp \\ Universidade Estadual de Campinas. \\ luciana.oliveira212b@gmail.com
}

INTRODUÇÃO: A Estratégia Saúde da Família (ESF) reordena as práticas de saúde, priorizando ações de promoção, recuperação e reabilitação da saúde e impactando nos determinantes e condicionantes de saúde da população. A equipe de enfermagem na ESF emprega em seu fazer tecnologias diferentes, pensando em uma lógica que reorganize e inove as práticas, promovendo o cuidar com responsabilização e exercendo a cidadania. OBJETIVOS: Analisar as práticas das auxiliares e/ou técnicas de enfermagem na Atenção Básica. METODOLOGIA: Pesquisa qualitativa, cujos dados coletados através de grupo focal com profissionais de enfermagem dos Centros de Saúde de Campinas/SP, foram gravados e analisados pela Análise de Conteúdo, modalidade Análise Temática. Aspectos éticos: CEP parecer $\mathrm{n}^{\circ}$ 1.041.224. RESULTADOS: No grupo focal foram apresentados os dados analisados da primeira etapa da pesquisa intitulada "Práticas da Enfermagem na Atenção Básica: inovação e trabalho", realizada com 150 auxiliares e técnicas de enfermagem. Participaram do grupo focal onze profissionais, definindo-se três categorias, a saber: - Atividade profissional essencialmente realizada pela enfermagem: Sala de vacina, prática considerada essencialmente realizada pela equipe de enfermagem, o profissional que atua na sala de vacinas deve ser capacitado e especializado, realizando-a com excelência; - Importância da equipe de enfermagem na atenção básica, presente em quase todos os setores dos Centros de Saúde, as auxiliares e técnicas de enfermagem demonstram sua capilaridade e inserção, sendo essencial para o funcionamento desses serviços, atrelando em seu fazer técnico diversas tecnologia; - Valorização profissional, a ESF permite a expansão do campo de atuação da enfermagem, contribuindo para modificar a percepção sobre 0 seu trabalho, promovendo a valorização profissional. CONCLUSÃO: As práticas das auxiliares e técnicas de enfermagem na Atenção Básica evidenciou a grande importância, capilaridade 
e inserção desses profissionais na equipe de saúde. Entretanto suas potencialidades ainda são pouco exploradas. Se faz necessário que esses profissionais se instrumentalizem nas tecnologias de relações, centrando as ações de saúde na lógica de produção de cuidado que se traduz no trabalho orientado as necessidades e a qualidade de vida do usuário.

Palavras-chave: Enfermagem de saúde pública. Prática profissional. Saúde coletiva 